14,09

\title{
Проявление низкоэнергетических ориентационных возбуждений в механически нагруженных аморфных полимерах по данным низкочастотной ИК- и раман-спектроскопии
}

\author{
(C) B.A. РЫжов \\ Физико-технический институт им. А.Ф. Иофффе РАН, \\ Санкт-Петербург, Россия \\ E-mail: v.ryzhov@mail.ioffe.ru
}

Поступила в Редакцию 23 декабря 2019 г.

В окончательной редакции 23 декабря 2019 г.

Принята к публикации 24 декабря 2019 г.

\begin{abstract}
Получены экспериментальные данные по влиянию механического нагружения (растяжения и сжатия) стеклообразного полиметилметакрилата и поливинилхлорида на низкочастотные ИК- и раман-спектры. Их анализ позволил обнаружить поглощение и рассеяние, обусловленные низкоэнергетическими ориентационными возбуждениями в неупорядоченном полимере, подверженном внешнему воздействию. Показано, что эти спектральные данные несут информацию о молекулярных механизмах деформации и релаксационной динамике макромолекул. Рассматривается возможный сценарий развития начальной стадии деформационного процесса.
\end{abstract}

Ключевые слова: ПВХ, ПММА, FIR- и раман-спектры, ориентационные возбуждения, бозонный пик, микроструктура.

DOI: 10.21883 FTT.2020.05.49254.661

\section{1. Введение}

Процесс деформирования стеклообразных полимеров запускает в своем развитии разные по масштабу и энергетике преобразования. От элементарных актов разрыва когезионных связей и роста амплитуд крутильноколебательного движения с переходом атомных групп из одного квазиустойчивого состояния в другое до нагружения и разрыва межатомных связей приводящего к разрушению полимера с дальнейшей потерей его механической стабильности.

Описанию деформационной реакции полимера при внешнем воздействии посвящено большое число теоретических и экспериментальных исследований, причем среди физических методов изучения элементарных актов деформирования наиболее информативной в настоящее время является колебательная спектроскопия. $\mathrm{C}$ eе помощью на частотах среднего ИК-диапазона были получены сведения о структурных изменениях в ориентированных частично-кристаллических полимерах, обусловленные поворотной изомеризацией и разрывом $\mathrm{C}-\mathrm{C}$-связей в основной цепи при их нагружении [1-4]. Роль межмолекулярных взаимодействий (ММB) и релаксационных переходов в конкретных модах деформации была исследована в работах Берштейна с привлечением, кроме ИК-спектроскопии [5,6], дифференциальной сканирующей калориметрии (ДСК) [7].

Так, к вопросу о молекулярной природе и механизмах деформации полимеров сформировалось несколько подходов. Механические свойства полимеров связываются с молекулярной подвижностью и с конформационными превращениями, разрывом химических связей и преодолением барьеров ММВ, с наличием свободного объема и особенностями надмолекулярного строения [8]. Существование разных точек зрения определяется не только сложностью проблемы, но и недостатком прямых экспериментальных данных по изучению деформационного процесса на микроуровне. Использование низкочастотного (терагерцевого) интервала длин волн $\left(3-250 \mathrm{~cm}^{-1}\right)$, позволяющего, помимо традиционных для спектроскопии полимеров задач, непосредственно анализировать молекулярную динамику и взаимодействия макромолекул и получать информацию о слабых возмущениях, которые имеют место в неупорядоченном полимере, подверженном внешнему воздействию, поэтому представляется актуальным.

В настоящее время усиление молекулярной подвижности в застеклованных полимерах связывают с проявляющимися в терагерцевом диапазоне низкоэнергетическими возбуждениями типа: а) малоугловой либрации звеньев цепи или молекул [6]; б) коррелированными колебаниями, представляющими избыточные колебательные состояния (бозонный пик (БП)) [9], и с) переориентационными процессами, представляющими быстрые релаксационные явления [10].

Еще в работе [11] было показано, что сравнительно небольшие деформации изменяют ИК-спектр ниже $250 \mathrm{~cm}^{-1}$, причем специфично для каждого полимера. Так, в спектре предварительно деформированного ПС увеличилась интенсивность полосы скелетных колебаний, тогда как параметры полос деформационных и крутильных колебаний боковых групп остались теми же, а спектр ПВХ, после вынужденно-эластической деформации свидетельствовал об ослаблении диполь- 
дипольных взаимодействий и увеличении интенсивности либрационного движения в основной цепи. В деформированном полиамиде-6 оказались нарушенными Н-связи и облегченными крутильные колебания полиметиленовых сегментов, тогда как в случае полиамида-12 уловить разрывы Н-связей удается лишь при измерениях под нагрузкой.

В работе [12] в низкочастотных раман-спектрах пластически деформированных ПММА и поликарбоната наблюдалось добавочное рассеяние, вызванное ориентацией ослабленных цепей, тогда как „бозонный пик“, отвечающий более упорядоченным наноструктурам изменил свои параметры только при деформации при $T>T_{g}$ (где $T_{g}$ - температура склеивания). Низкочастотные раманспектры ПММА под нагрузкой [13] обнаруживают рост квазиупругого рассеяния и при $T<T_{g}$, обусловленный увеличением числа релаксационных центров - неравновесных состояний ориентационного типа.

В настоящей работе получены и проанализированы низкочастотные ИК- и раман-спектры ПММА, подвергнутого вынужденно-эластической деформации, и ПВХ под нагрузкой в квазиупругом режиме с целью дальнейшего исследования молекулярных механизмов деформации полимеров.

\section{2. Методика}

Спектральные приборы и условия записи спектров на них рассматривались, например, в [9], там же обсуждается возможность корректного сопоставления ИКи раман-данных на низких частотах. Для получения ИК-спектров использовались образцы в виде пленок толщиной $\sim 100 \mu \mathrm{m}$, которые в случае ПВХ отливались из раствора в дихлорэтане, а из блочного ПММА прессовались при $T \approx 150^{\circ} \mathrm{C}$ и давлении $150 \mathrm{kgs} / \mathrm{cm}^{2}$.

Образцы отжигались в течение часа при температурах на $10-20^{\circ}$ выше $T_{g}$. Для получения FIR- и раман-спектров использовались также образцы в виде цилиндров диаметром 12 и высотой $15 \mathrm{~mm}$. Пленки и цилиндры деформировались путем их одноосного сжатия между такими же цилиндрами из ПММА. Подобный пакет деформируется с образованием „бочки“ как единое целое. Его остаточная деформация рассчитывалась по изменению диаметра (от $d_{0}$ к $d$ ) по формуле $\varepsilon_{\text {ост }}=\left(1-d_{o}^{2} / d_{2}\right) \times 100 \%$. Для записи спектров ПВХ под нагрузкой образцы, вырезанные в виде полосок размером $10 \times 15 \times 0.1 \mathrm{~mm}^{3}$, подвергались одноосному растяжению на специальном устройстве в кюветном отделении спектрометра, обеспечивающем поддержание постоянного напряжения на образце. Все спектры были получены при комнатной температуре; в каждом случае проводилось не менее трех повторных опытов. Спектры записывались с разрешением $1-2 \mathrm{~cm}^{-1}$ при отношении сигнал/шум порядка 100. Погрешность измерения частоты составляла $2-3 \mathrm{~cm}^{-1}$, погрешность измерения коэффициента поглощения $k=(t)^{-1} \ln \left(I_{0} / I\right)$, где $I_{0}$ и $I-$ интенсивности падающего и прошедшего через образец толщиной $t$ излучения, соответственно, составляла $5-10 \%$.

\section{3. Результаты и их обсуждение}

На рис. 1 показано, как в FIR-спектре ПВХ под нагрузкой изменяется контур полосы поглощения при $\sim 185 \mathrm{~cm}^{-1}$, которую относят к проявлению колебательного, либрационного движения в цепи группы $\mathrm{CH}_{2}-\mathrm{CHCl}$, (см. фрагмент структурной формулы), т.е. монозвена ПВХ на межмолекулярных связях типа $\mathrm{CH} \ldots \mathrm{Cl}[14]$.

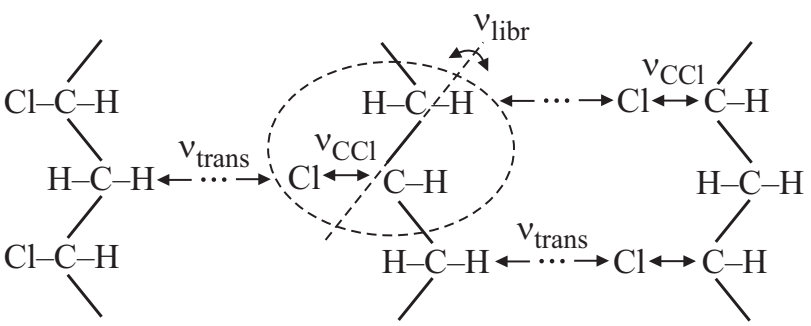

Это отнесение подтверждается корреляцией спектральных параметров полосы с моментом инерции либратора (мономерного звена ПВХ) и его дипольным моментом. Трансляционное движение группы $\mathrm{CH}_{2}-\mathrm{CHCl}$ проявляется в FIR-спектре ПВХ при 64 и $90 \mathrm{~cm}^{-1}$ [6]. Дублетный контур трансляционной и либрационной полос демонстрирует чувствительность подвижности мономерного звена к конформационному состоянию основной цепи.

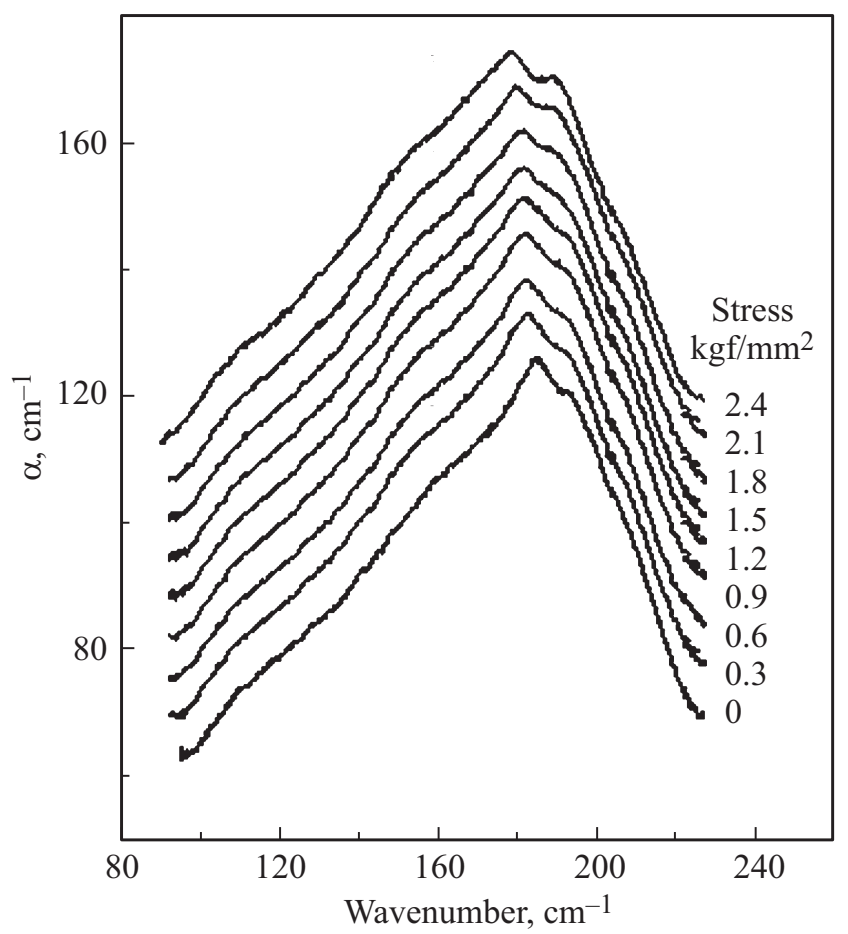

Pис. 1. Полоса крутильных колебаний при $185 \mathrm{~cm}^{-1}$ в FIR-спектре поливинилхлорида при последовательных уровнях нагружения. Спектры получены с разрешением $0.5 \mathrm{~cm}^{-1}$. Контура последовательных уровней нагружения смещены по вертикали на $k=6 \mathrm{~cm}^{-1}$. Частота пика поглощения варьируется от $185 \mathrm{~cm}^{-1}$ при нулевой нагрузке до $177 \mathrm{~cm}^{-1}$ при напряжении $2.4 \mathrm{kgs} / \mathrm{mm}^{2}$. 
В частности, компоненты либрационной полосы при 185 и $192 \mathrm{~cm}^{-1}$ характеризуют, соответственно, gauche- и trans-последовательности в макромолекулах ПВХ.

Как видно из рис. 1 уже небольшие (порядка $0.1 \sigma_{\mathrm{B}}$ предела вынужденной эластичности) нагрузки приводят к смещению дублета при $185 \mathrm{~cm}^{-1}$ к низким частотам и к одновременному увеличению полуширины всей полосы. То есть, наблюдается эффект, подобный влиянию температуры, вызывающей при ее повышении, снижение потенциального барьера для либрационного движения в цепи и рост амплитуды этого движения.

Помимо сдвига и уширения полосы, пропорционального в режиме упругого растяжения величине нагрузки, все более проявляется асимметрия полосы при $185 \mathrm{~cm}^{-1}$. Ее низкочастотное оттенение, вызванное переходами с высших колебательных уровней, делается еще сильнее, так как вклад таких „горячих“ переходов с увеличением температуры и запасенной в нагруженном полимере энергии становится больше.

При приближении нагрузки к пределу упругости, начиная с $\sigma \approx 0.6 \mathrm{~B}$, в спектре также изменяется распределение интенсивностей в дублете в пользу его высокочастотной компоненты, отвечающей либрации звеньев в более вытянутых участках углеродной цепи. Очевидно, с исчерпанием к этому моменту возможностей упругого изменения углов и длин нагруженных скелетных связей, дальнейшая деформация, повышающая амплитуду либрационного движения в макромолекулах, облегчает проскальзывание цепей и приводит к их развертыванию и распрямлению. Снятие растягивающего напряжения возвращает цепи в изначальное низкоэнергетическое конформационное состояние, что и проявляется в обратимом изменении всех параметров либрационной полосы в FIR-спектре ПВХ.

Переходя далее к рассмотрению влияния вынужденноэластической деформации $\left(\sigma>\sigma_{\mathrm{B}}\right.$ на низкочастотные ИК- и раман-спектры отметим, что в этом случае исследуемый образец восстанавливал свою исходную форму и спектр лишь при длительном „отдыхе“ после отжига при $T>T_{g}$. В уже цитировавшихся выше работах показано, что с переходом предела вынужденной эластичности в деформированном образце не только ослабевает, но и существенно нарушается прежняя система межмолекулярных связей. Сетка физических узлов становится более редкой, обеспечивая повышенную (в том числе надбарьерную) подвижность, как звеньев, так и сегментов цепи. При деформации $\varepsilon>7 \%$ процесс ,пластичности“ развивается не только за счет растяжения, распутывания и проскальзывания макромолекул, но и сопровождается их разрывом. На макроуровне он приводит к ориентации и распаду ламелей, образованию сдвиговых деформационных зон, крейзов и несплошностей.

Рассмотрим, как повлияли эти процессы на FIR(рис. 2) и раман-спектры (рис. 3) предварительно деформированного сжатием ПММА с остаточной деформацией 25,30 и $43 \%$.

Из рис. 2 и 3 видно, что по сравнению с исходными, низкочастотные спектры предварительно дефор- мированных образцов изменяют свой контур в промежутке между частотами проявления либрации мономерных звеньев $\left(n_{\text {libr }} \sim 90 \mathrm{~cm}^{-1}\right)$ и либрации участка цепи $\left(v_{\text {Бп }} \sim 20 \mathrm{~cm}^{-1}\right)$. При этом $v_{\text {libr }}$ испытывает „красный сдвиг на $3 \sim 5 \mathrm{~cm}^{-1}$, а также растет интенсивность

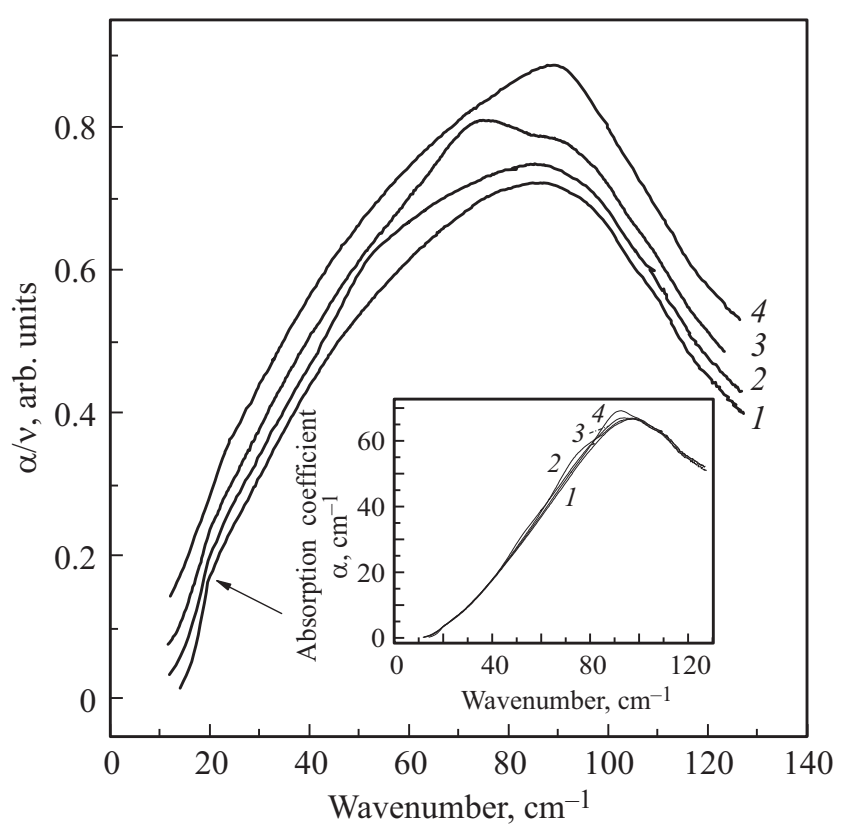

Рис. 2. Экспериментальные (вставка) и в приведенных координатах $\alpha / v$ FIR-спектры исходного (1) и деформированного на 30\% ПММА (3). (2) и (4) - FIR-спектры олигомеров ПММА со степенью полимеризации $n=7$ и 2. Приведенные спектры смещены по вертикали. Положение БП показано стрелкой.

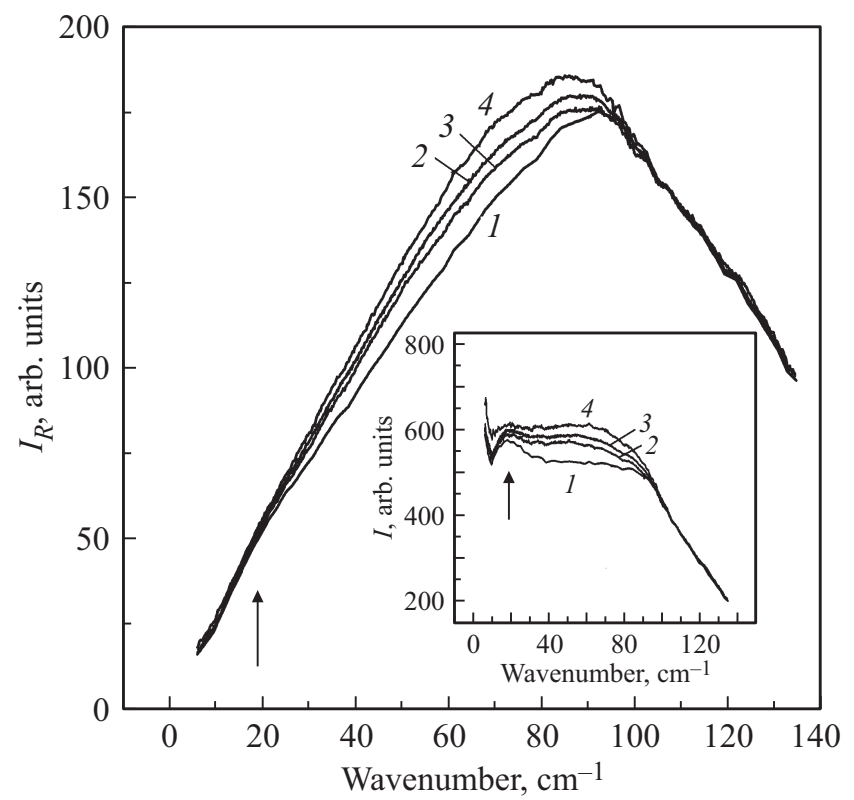

Рис. 3. Экспериментальные (вставка) и приведенные раманспектры исходного (1) и деформированного на $25 \%$ (2) и 43\% (4) ПММА. (3) - раман-спектр пластично деформированного ПММА из работы [12]. Положение БП в спектрах показано стрелкой. 

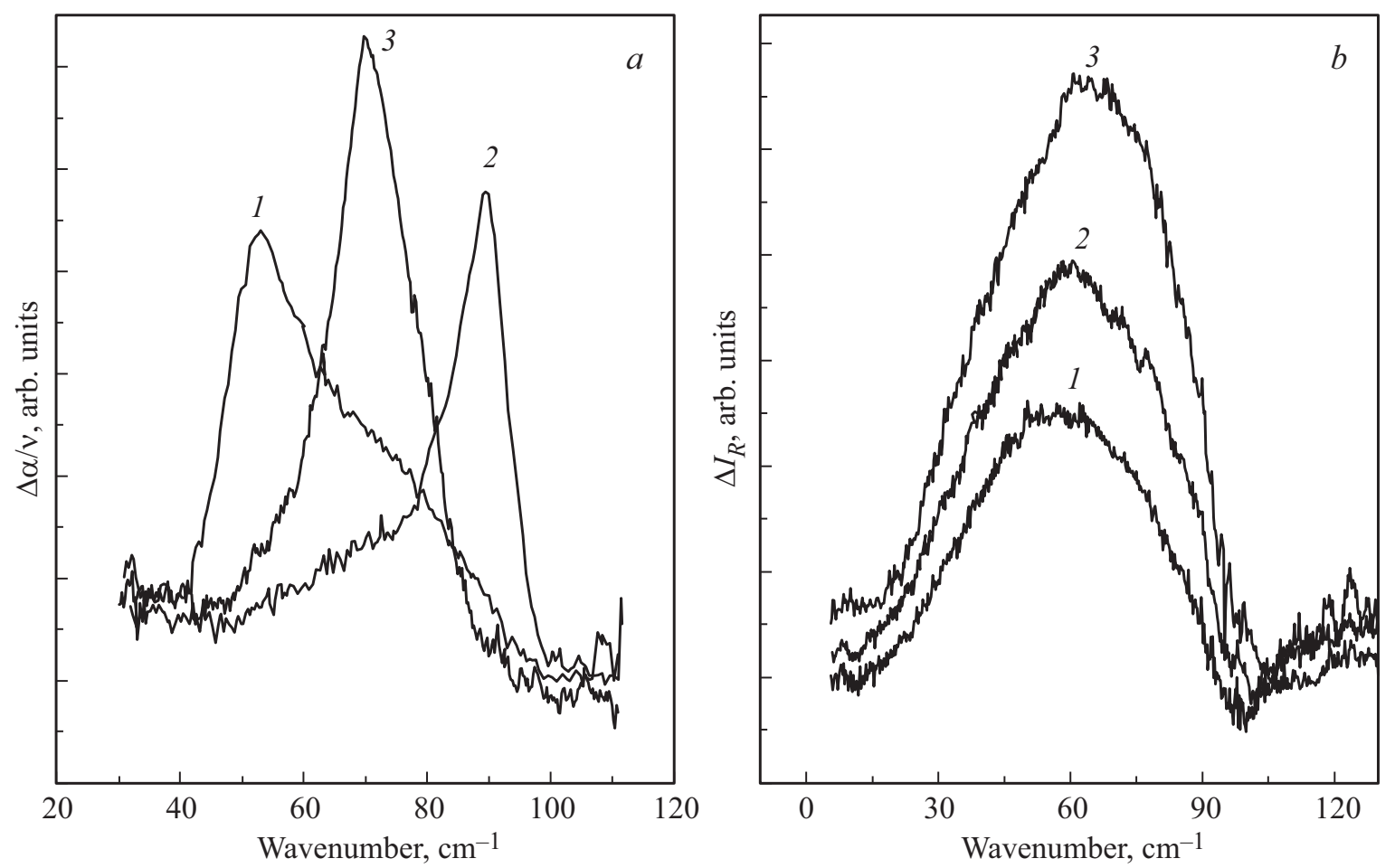

Pис. 4. (a) Разностные FIR-спектры: (1) между исходным и деформированным на 30\% ПММА и между ПММА и его олигомерами в 7 (2) и 2 (3) мономерных звеньев. (b) Разностные раман-спектры: между спектром полимера до и после его деформирования на 25 (1) и 43\% (3). (2) разностный приведенный раман-спектр пластически деформированного ПММА из работы [12].

рассеяния на частотах ниже $v_{\text {БП }}$, постепенно скрывая сам бозонный пик.

Наблюдаемые в спектрах деформированных образцов изменения показаны на рис. 4 в виде разностных (между исходным и деформированным образцами) приведенных спектров. Заметим, что использование раман- и FIR-данных в приведенных координатах $I(v)[1-\exp (-\hbar v / k T)]$ и $k / v$ соответственно, необходимо для их корректного сопоставления друг с другом. На этих врезках, кроме того, представлены: разностный приведенный раман-спектр пластически деформированного ПММА из работы [12] и разностные (между полимером и олигомерами) приведенные FIR-спектры олигомеров ПММА в 2 и 7 мономерных звеньев из работы [15].

Появление дополнительного рассеяния в раманспектре пластически деформированного ПММА в [12] было связано с ориентацией рассеивающих центров, индуцированных в полимере при его нагружении, а его локализация в области $\sim 55-75 \mathrm{~cm}^{-1}$ с тем, что ответственными за это рассеяние являются междоменные так называемые проходные, более короткие, чем в случае БП, цепи.

Последнее, похоже, подтверждается наличием дополнительного поглощения в том же интервале частот в FIR-спектрах олигомеров ПММА со степенью полимеризации $n=2$ и 7 (см. рис. 4,a). К проявлению укороченных (разрывом или стерически) либрирующих сегментов цепей может быть, следовательно, отнесена и увеличивающаяся с ростом остаточной деформации интенсивность в области $\sim 40-80 \mathrm{~cm}^{-1}$ в спектрах предварительно нагруженных образцов.

Дополнительное поглощение в FIR- (рис. 4, $a$, кривая 3) и рассеяние в раман-спектрах (рис. $4, b$, кривые 1,2 и 3), судя по их промежуточному положению, обусловлено, таким образом, появлению в полимере при его нагружении более коротких (в 3-4 звена) цепей.

Наличие низкомолекулярных образований в нагруженном ПММА отражается также в увеличении интенсивности квазиупругого рассеяния на частотах ниже БП, поскольку, как показано в работе [16], выступая в роли дефектов, они способствуют росту числа температурноактивированных релаксаторов.

В свою очередь, присутствие подобных дефектов свидетельствует об ослаблении сетки межмолекулярных связей и барьеров в таком полимере. Отсюда ангармонизм либрационного движения в макромолекулах и связанные с ним уширение полосы при $\sim 95 \mathrm{~cm}^{-1}$ и низкочастотный сдвиг ее максимума.

Другой эффект - рост интенсивности рассеяния в раман-спектрах и поглощения в FIR-спектрах предварительно нагруженного ПММА на частотах ниже БП (рис. 1 и рис. 2). Ранее подобный эффект наблюдался в рамановских спектрах полимеров при повышении температуры [17] и в FIR-спектрах ПММА при переходе к спектрам его олигомеров [15]. Согласно этим исследованиям, увеличение интенсивности на частотах ниже БП обусловлено растущим с температурой и де- 


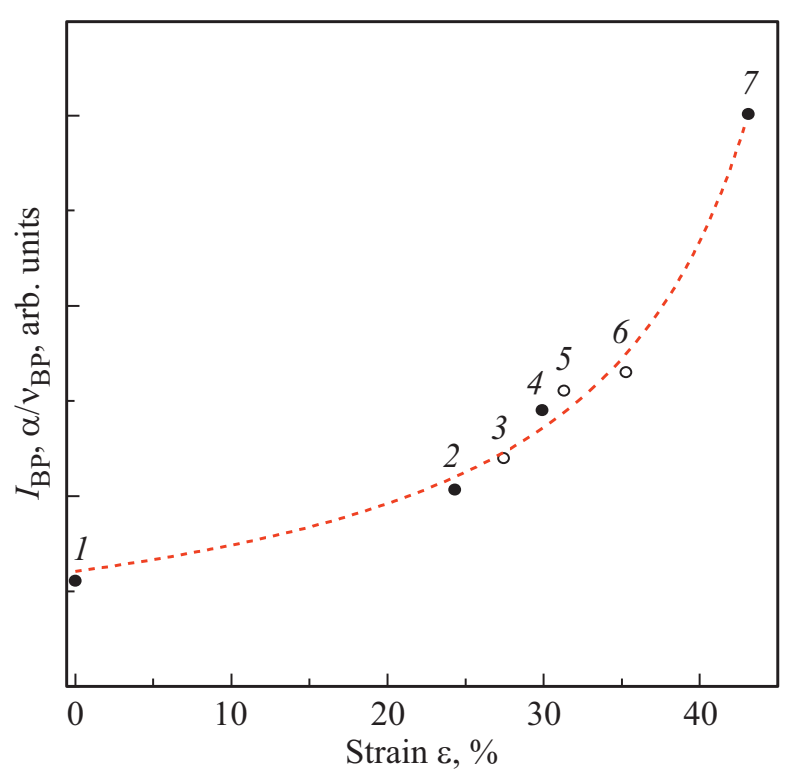

Рис. 5. Зависимость интенсивности бозонного пика в раман- (точки 1, 2, 4, 7) и FIR- (точка 5) спектрах ПММА от величины остаточной деформации $\varepsilon$; точки 3 и 6 интенсивности БП в FIR-спектрах димера и семимера ПММА соответственно.

полимеризацией вкладом релаксационной подвижности. График рис. 5 показывает, что этот вклад, вызванный вынужденно-эластической деформацией, не является монотонным. В нем прослеживается участие, по крайней мере, двух релаксационных процессов.

Таким образом, даже небольшая вынужденно-эластическая деформация приводит к существенному изменению низкочастотных спектров ПММА, которые показывают, что при этом, кроме усиления колебательного (либрационного) движения мономерных звеньев, способствующего образованию ориентационных и диссоционных дефектов, в предварительно нагруженном полимере имеет место повышенная релаксационная подвижность.

\section{4. Заключение}

Итак, внешняя нагрузка в режиме упругого растяжения в случае ПВХ, судя по изменениям в его FIR-спектре, привела к снижению потенциального барьера для либрации и росту амплитуды этого движения, обеспечивающему повышенную конформационную подвижность цепей. Вынужденно-эластическая деформация (на примере ПММА), нарушив прежнюю сетку физических узлов, сделала эти изменения необратимыми, а новые ослабленные связи облегчили диссоциацию меж молекулярносвязанных сегментов цепей, их ориентацию и деполимеризацию. Уменьшение энергии активации релаксационной подвижности возле этих дефектов в свою очередь привело к увеличению числа релаксирующих центров и пропорциональному их числу росту интен- сивности квазиупругого рассеяния в низкочастотном спектре нагруженного полимера.

В целом, проведенное изучение низкочастотных FIRи раман-спектров нагруженных (ПВХ) и предварительно деформированных (ПММА) полимеров иллюстрирует нетривиальные возможности этого частотного диапазона, позволяющего непосредственно анализировать молекулярную динамику, межцепные и внутримолекулярные взаимодействия.

\section{Конфликт интересов}

Автор заявляет, что у него нет конфликта интересов

\section{Список литературы}

[1] И.И. Новак. Высокомолекуляр. соединения 5, 1645 (1963).

[2] С.Н. Журков, В.И. Веттегрень, В.Е. Корсуков, И.И. Новак. ФТТ 11, 2, 290 (1969).

[3] В.И. Веттегрень. Канд. дис. ФТИ, Л., 1970.

[4] П.М. Пахомов, М.И. Шерматов, В.Е. Корсуков, В.С. Куксенко. Высокомолекуляр. соединения 18А, 132 (1976).

[5] В.А. Берштейн, В.М. Егоров, В.А. Рыжов, А.Б. Синани, В.А. Степанов. ФТТ 23, 6, 1611 (1981).

[6] V.A. Bershtein, V.A. Ryzhov. Adv. Polym. Sci. 114, 43 (1994).

[7] V.A. Bershtein, V.M. Egorov. Differential Scanning Calorimetry of Polymers. N. Y. (1994). 253 p.

[8] L. Monnerie, J.L. Halary, H.H. Kausch. Adv. Polym. Sci. 187, 215 (2005).

[9] В.А. Рыжов, В.А. Берштейн. ФТТ 50, 1901 (2008).

[10] В.А. Рыжов. ФТТ 59, 7, 1422 (2018).

[11] В.А. Берштейн, В.А. Рыжов. Высокомолекуляр. соединения 24, 495 (1982).

[12] A. Mermet, E. Duval, S. Etienne, G'Sell C. J. Non-Crystalline Solids 196, 227 (1996).

[13] K. Kober, A. Tshmel. J. Pol. Sci. 38, 1133 (2000).

[14] M. Goldshtein, D. Stephenson, W. Maddams. Polymer. 24, 823 (1993).

[15] В.А. Рыжов. Опт. и спектр. 126, 895 (2019).

[16] V.N. Surovtsev, A. Mermet, E. Duval, V.N. Novikov. J. Chem. Phys. 104. 6818 (1996).

[17] V.N. Novikov, A.P. Sokolov, B. Stube, N.V. Surovtsev, E. Duval, A. Mermet. J. Chem. Phys. 107, 1057 (1997).

Редактор К.В. Емщев 